\title{
Accelerated learning techniques for the foreign language classroom
} W. Jane Bancroft

\begin{abstract}
Recently researchers and teachers have noticed that more and more students have trouble learning. The causes for poor student learning are many and varied. To remedy the situation, programmes have been implemented in many educational institutions to reduce stress and improve concentration, and to accelerate learning. The author suggests accelerated learning techniques for the foreign language classroom.
\end{abstract}

In die jongste tyd het navorsers en onderwysers opgemerk dat steeds meer studente probleme het met leer. Die oorsake hiervoor is menigvuldig en uiteenlopend van aard. In 'n poging om die situasie te verbeter, is daar met programme begin om spanning in die opvoedingsituasic te verminder, sowel as om konsentrasie te verbeter en die leerproses te versnel. Die skrywer bespreek enkele tegnieke vir versnelde leerprosesse in vreemdetaalonderrig.

In recent years, researchers and teachers in many countries have noticed that more and more students have trouble learning. The causes for poor student learning are no doubt many and varied, but would certainly include (in addition to such obvious ones as drugs and alcohol) junk foods and/or poor nutrition, lack of exercise, physical and psychological stress and, in the opinion of Marshall McLuhan, a short concentration span-often induced by the watching of too much television. To remedy the situation, programmes have been, and are being implemented in many educational institutions to reduce stress and improve concentration, on the one hand, and to accelerate learning, on the other.

Accelerated learning (or "superlearning") techniques may be divided into two categories: (1) those which serve as a preliminary to learning; (2) those which apply specifically to the learning of a given discipline, say, a foreign language. Preliminary techniques include: physical relaxation; mental relaxation (or mind-calming); breathing exercises (including co-ordination of breathing with mental and physical activity); outward concentration exercises; visualization (or inner concentration) exercises. Those techniques or approaches which apply specifically to language learning are adapted from Sophrology, a system founded by a Colombian medical doctor and therapist, Caycedo $^{1}$, and Suggestology/Suggestopedia, a system founded by Lozanov, a Bulgarian medical doctor and therapist. ${ }^{2}$ Both methods are based on raja yoga and involve learning in two complementary states of consciousness: a wide-awake, alert level and a deeper, more relaxed level. ${ }^{3}$ Studies that have been conducted in the United States by researchers affiliated with the Society for Accelerative Learning and Teaching have shown, for example, that adaptations of Suggestopedia, when properly used by a competent and personable teacher, have speeded up learning and improved retention by 2,5 to 3 times. 4

Experts recommend that physical relaxation should precede mental relaxation which, in turn, should precede concentration exercises. (The Chinese know this and, in the People's Republic of China, students are put through 20 minutes of special exercises every morning, before classes begin, and every three to four hours thereafter.) Sample physical activities include: stretching exercises; jumping on the spot; shaking out the tension in the arms and legs. Neck rolls and the progressive 
relaxation exercise (in which the key areas of the body from feet to head are relaxed in turn) may be performed while the students are seated comfortably, but with a good posture, in their chairs. Mindcalming exercises comprise "seeing" a little white cloud moving in the sky on a warm summer's day or climbing an imaginary mountain to watch a beautiful sunrise. An exercise such as "early pleasant learning recall" in which the students are encouraged to return to a past childhood situation where learning was pleasurable, not only induces a state of mental relaxation but also improves student motivation. ${ }^{5}$

It is very important for students to be in a wellventilated classroom, seated in an erect posture and breathing properly if concentration and learning are to occur. Books on yoga may be consulted for breathing techniques, but the main points are: breathing through the nose; breathing slowly and deeply from the abdomen; and breathing in a rhythmic manner, by harmonizing the three "moments": inhalation, retention of the inhaled air and exhalation. Sample breathing exercises include having the students (1) concentrate on their breathing for 30 seconds, visualizing the air inside them; (2) check their pulse beat and make their breathing rhythm coincide with their heart rate; (3) count the number of breaths they take within one minute. The next step is to co-ordinate breathing with mental and physical activity. Physical activities might include synchronizing breathing with four separate movements: get up, raise your arm, sit down, pick up a pencil; inhale while executing the first two movements, pause (and hold breath), exhale while performing the last two movements. Mental activities could comprise reading a text while counting the number of breaths one takes; co-ordinating breathing rhythm with pulse rate and at the same time reading a lesson paragraph; copying down several lines from a book.while breathing slowly and deeply. ${ }^{6}$

Another useful set of preliminary exercises involves the harmonization of breathing with outward concentration. For example, on a wavy line marked as follows:

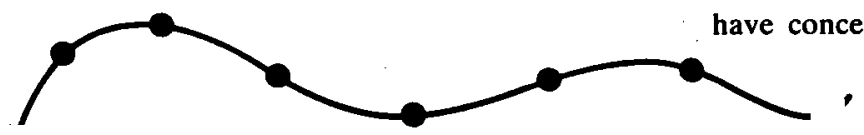

Students may be asked to breathe in from left to right and then to breathe out from right to left, while their gaze moves slowly from point to point along the line. The teacher may draw on the blackboard two figures linked by a vertical line of about one metre in length:

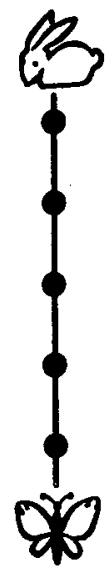

The students are asked to exhale, look at the lower drawing and inhale slowly while moving their gaze up the line, point by point. When the upper design is reached, the students look at it, hold their breath and then commence a slow exhalation while moving their glance back down the line, point by point, until the lower design has been reached. After a several seconds' pause, the exercise begins again. (Students can move their heads or their eyes alone during this exercise.)

Concentration exercises begin with fixing one's outward attention on geometric shapes or patterns, reminiscent of the mandala. For example, in the following design:

-

Students are asked to concentrate on the small dot situated in the centre of the figure at the right (30 seconds). Then they are asked to transfer their gaze to the dot at the left of the design. (If the students have concentrated properly on the figures, they 
should see, on the left, the same figure as on the right, except that the colours are reversed.)

Another sample exercise involves both outer and inner concentration:
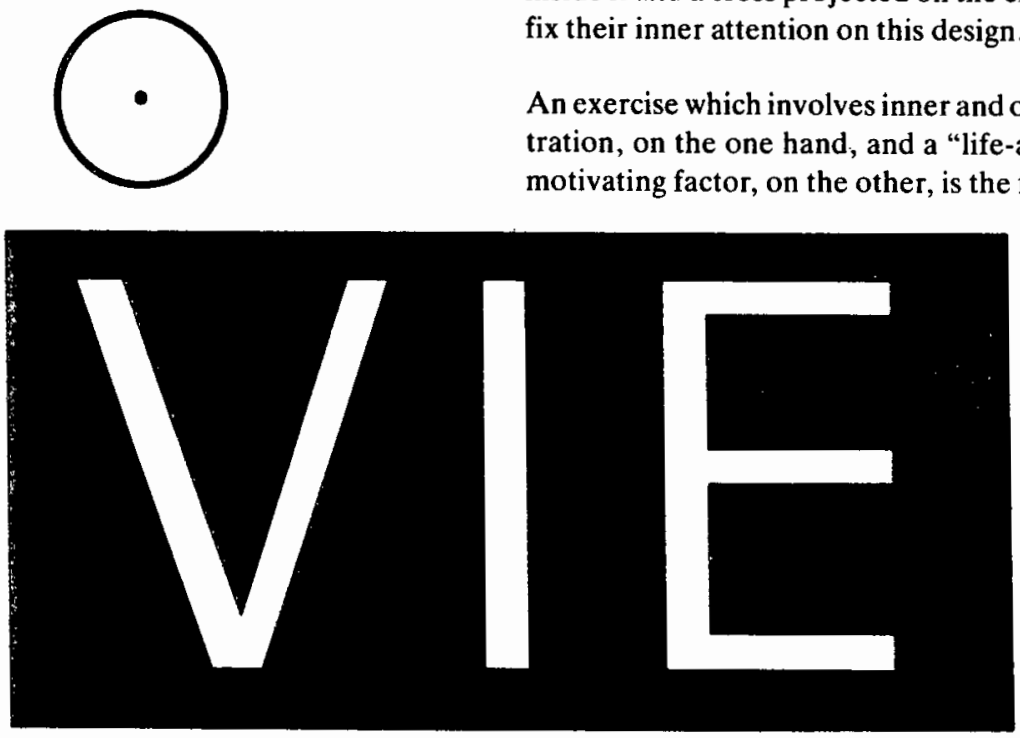

The students are asked to concentrate on the black circle and then to try to project a cross onto the inside of it, cutting through the dot. Then the students, with eyes closed, are asked to visualize the same geometric shape-a circle with a dot inside it and a cross projected on the circle-and to fix their inner attention on this design.

An exercise which involves inner and outer concentration, on the one hand, and a "life-affirming" or motivating factor, on the other, is the following:
Concentrate your attention on the word VIE (one minute). Now close your eyes and relax your eyelids. Imagine a white screen on which the word VIE is printed in black. Let the word disappear. With your eyes closed, recreate a white screen. Project the word VIE in black on this screen. Visualize clearly the separate letters. Keep this word in your mind's eye as long as possible.

A sample visualization exercise involves having the students choose two mental images, say, two different objects or two different geometric shapes (a blue circle, a green square). The students are asked to close their cyes, relax their eyelids and breathe slowly and deeply from the abdomen. As the students breathe in, they are asked to visualize clearly one of the two images. As they hold their breath, they visualize this inner image. While breathing out, they clearly visualize the second image, as if they were "changing slides". During a pause between breaths, they continue to visualize the second image. Next they breathe in and clearly visualize the first image once again, as the exercise is repeated. ${ }^{7}$

Now that the students have performed the preliminary exercises, they are ready to become acquaint- ed with the Sophrology memory training system (Entrenamiento Sofrológico de la Memoria) and with Suggestopedia, two methods which, as previously mentioned, involve learning in two complementary states of consciousness: outer concentration on the text and inner visualization of the text. While Suggestopedia is ideally suited to rote memorization of basic factual materials andis what one might term "teacher-directed", the Sophrology memory training system is designed to improve the memory in a global sense and is what one might call "inner-directed".

The Sophrology memory training system is derived from Japanese Zen and from the third degree (or part) of Caycedo's dynamic relaxation programme. ${ }^{8}$ For therapeutic and pedagogical reasons, Caycedo insists on the positive aspects of memory (for example, positive, as opposed to negative or "neutral" sensations). He believes that memory has five functions: (1) evocation of a positive sensation from the past; (2) fixation or concentration on this positive sensation; (3) association of colours, objects, persons with this positive sensation; (4) repetition, so that the positive sensation can be impressed on the mind; (5) presentation of an amplification or summary of this positive 
sensation in written or oral form. In the classroom, the Caycedo system for memory training uses study or exam situations, instead of personal or therapeutic ones. Once the students have been properly trained, they are able, just before an examination, to visualize themselves in the appropriate posture and to put themselves mentally into the appropriate state of relaxed alertness.

Caycedo believes that the physical and psychological aspects of man are inseparably linked and that the body is an ideal instrument for developing or training the memory. Important "body elements" for memory training are: abdominal respiration and co-ordination of breathing with thought or image; proper cerebral circulation (as aided, for example, by the relaxation of the neck muscles); correct posture(s). A standing posture is used for relaxation exercises; two seated postures are used for memory training. An inclined seated posture, with eyes closed, is used for evocation, fixation and association. A modified Zen posture, with back straight up and eyes open, knees bent and feet under the chair, is used for repetition and/or organization. In Sophrology (in contrast, as we shall see, to Suggestopedia) one normally moves from a deeper level of consciousness to a relaxed but nonetheless alert state.

Originally developed for therapeutic purposes, the Sophrology memory training system can also be used for studying printed materials. If such is the case, the postures and the corresponding levels of consciousness are reversed. First, one looks at the material (a language dialogue, for example) with intense concentration and in an upright posture; secondly, one closes one's eyes and, in an inclined seated posture, one "visualizes" the main points (or the precise words) of what one has just read, by projecting these onto an inner mental screen. Then, with eyes open, one rereads the material to see if it has been fully "registered". In contrast to Suggestopedia, no music is used as background in Sophrology and the student can move at his or her own pace.

As developed at the Institute of Suggestology in Sofia, Bulgaria in the late 1960's and early 1970's by Aleko Novakov and his colleagues, under Lozanov's direction, the original suggestopedic language class featured a special relaxation session for unconscious assimilation of the lesson material.
The session was usually the conclusion of a threepart intensive class that also included conversational review and presentation of new material. To help overcome inhibitions and to allow for more spontaneous expression in the classroom, each student was given a new name and a new (foreign) identity-French, English, Italian, etc. The new material presented to the students consisted largely of dialogues based on "real life". The dialogues involved general or universal situations (home, family, daily activities, renting a hotel room, eating in a restaurant, city and country tours, cultural events) and were designed to stimulate positive emotions in the students. ${ }^{9}$

The third part of the suggestopedic language class, the session or séance as it was known, was originally divided into two parts, active and passive, with each part comprising twenty minutes, the ideal meditation period in yoga. During the active part (i.e. the period of active or outward concentration on the text), the teacher presented the appropriate foreign-language words or phrases with three different yogic intonations-declarative, whisper, loud command-while the students looked at the dialogue on the printed page and repeated to themselves (using inner speech) the appropriate foreign-language words and phrases. During the passive part (i.e. the period of inner concentration on the text), the teacher read the language dialogue a second time but now in a soft, soothing voice over a background of slow movements (MM 60) from baroque chamber music for stringed instruments, while the students, with eyes closed and in a relaxed posture, meditated on the text.

In the two parts of the session, the material was presented rhythmically on an eight-second cycle: two seconds-translation; four seconds-foreignlanguage phrase; two seconds-pause. The students were trained to breathe deeply and rhythmically in accordance with the teacher's voice and/or the baroque slow movements. (A rhythm of MM 60 , or 60 beats to the minute, is considered, in Indian philosophy, to be the ideal beat for meditation.) During the concert session, in particular, the lyrical and rhythmic music, the artistic and rhythmic rendering of the text by the teacher, the rhythmic, deep breathing and meditative state of the students contributed (and contribute) to a marked decrease in fatigue and tension and a marked increase in the memorization of foreign-language materials. 
It is, of course, not possible in a foreign-language class of fifty minutes' duration to put the students through a lengthy series of physical and mental relaxation exercises. Nor is it possible, except in an immersion programme, to utilize all the appropriate aspects of Sophrology and Suggestopedia. However, I have found in my language classes that it is possible, on a regular basis, to incorporate a few relaxation exercises into the classperiod, to insist on good posture and proper breathing techniques and to utilize what might be termed a minisession, in which the text, once it has been thoroughly analyzed, is read over a background of baroque music in a soft and persuasive voice. In my opinion, suggestopedic/sophrological techniques definitely improve the class atmosphere and student performance, even when these techniques are limited to (or by) the traditional foreign-language classroom."

\section{Notes}

1 For a thorough, but nonetheless readable account of Sophrology, see: Henri Boon, Yves Davrou and Jean-Claude Macquet, La Sophrologie (Paris: Editions Retz, 1976).

2 Sce: Bagriana Bélanger, La Suggestologie (Paris: Editions Retz, 1978). Bélanger's book is much better organized and much easier to read than the English translation of Lozanov's thesis (Suggestology and outlines of Suggestopedy [New York: Gordon and Breach, 1978]). See, also, an important bibliography by Milla Bayuk: Suggestology and Suggestopedia: A selective bibliography of Western sources, ERIC Documents on Foreign Language Teaching and Linguistics, 1980, ED 192 556. (The ERIC Clearinghouse on Languages and Linguistics, Center for Applied Linguistics, 3520 Prospect Street, N.W., Washington, D.C., has probably the largest collection of articles in microfiche and hard copy on Suggestopedia, Accelerative Learning and related matters.)

3 For a comparison of five methods based in whole or in part on unconscious assimilation (i.e. Sug-

gestology/Suggestopedia, Sophrology, the Tomatis method, Soviet hypnopedia, the Suzuki approach), see $W$. Jane Bancroft's article: Unconscious Assimilation in Foreign Language Learning, New approaches in foreign language methodology (15th AIMAV Colloquium), ed. Wil Knibbeler and Marij Bernards (Nijmegen: University of Nijmegen, 1984), pp. 18-24.

4 See Bancroft's article, The Lozanov method and its American adaptations, The Modern Language Journal, 62 (1978), pp. 167-75.

5 The mental relaxation exercises, in particular, are taken from: Donald H. Schuster, Ray BenitezBordon and Charles Gritton, Suggestive-Accelerative Learning and Teaching: A manual of classroom procedures based on the Lozanov method (Des Moines: Society for Suggestive-Accelerative Learning and Teaching, 1976). A new edition is to appear in 1985, under the direction of Donald Schuster, Professor of Psychology at Iowa State University and one of the pioneers in accelerative learning in the United States.

6 Most of these exercises are taken from an interesting work by Jacques de Coulon, Eveil et Harmonie de la Personnalité: Culture physique et psychique par la Méthode arc-en-ciel (Lausanne: Editions du Signal, 1977).

7 Concentration and visualization exercises are taken from Jacques de Coulon's book which is available, along with many other materials of a similar nature, from Micheline Flak, Groupe de Recherche sur le Yoga dans l'Education, Collège Condorcet, 61, rue d'Amsterdam, Paris.

8 For more information on the Sophrology memory training system, see: Yves Davrou and Françoise Leclerq, Les Etonnantes Possibilités de votre Mémoire par la Sophrologie (Paris: Editions Retz, 1982). See, also, Bancroft's article: Caycedo's Sophrology and Lozanov's Suggestology: Mirror images of a system, ERIC Documents, 1979, ED 183033.

9 or more information on the original suggestopedic system, see my article: The Lozanov language class, ERIC Documents, 1975, ED 108475.

10 For further discussion of this issue, see my article: Suggestopedia, Sophrology and the traditional foreign language class, Foreign Language Annals, 15 (1982), 373-79. 